\title{
A high responsivity, broadband waveguide uni-travelling carrier photodiode (invited paper)
}

\author{
C. C. Renaud (1), M. Robertson (2), D. Rogers (2), R. Firth (2), P. J. Cannard(2), R. Moore(2), A. J. \\ Seeds (1)
}

1 : Ultra-Fast Photonics Group, Dept of Electrical and Electronic Engineering, University College London, Torrington Place, London WC1E 7JE, UK, Tel: +44(0)20 7679 4464, Fax +44(0)20 7388

9325 email: a.seeds@ee.ucl.ac.uk

2 : Centre For Integrated Photonics, michael.robertson@ ciphotonics.com

\begin{abstract}
:
A $0.2 \mathrm{~A} / \mathrm{W}$ responsivity waveguide-uni-travelling carrier photodiode with a $\mathbf{- 3} \mathrm{dB}$ electrical frequency response > $107 \mathrm{GHz}$ is demonstrated. Up to $-5 \mathrm{dBm}$ electrical power at $110 \mathrm{GHz}$, and $28 \mathrm{~mA}$ photocurrent (DC excitation) were detected. The photodiode was also integrated with an antenna to permit a record breaking emission of up to $148 \mu \mathrm{W}$ at $457 \mathrm{GHz}$ and $25 \mu \mathrm{W}$ at $914 \mathrm{GHz}$.
\end{abstract}

Keywords: Photodetector, millimetre-wave, THz source, Heterodyne source, semiconductor.

\section{INTRODUCTION}

There is an increasing demand for photodetectors able to detect signals modulated at frequencies above $40 \mathrm{GHz}$ with good linearity and high output power, in order to achieve high dynamic range and high signal to noise ratio for applications such as mm-wave or fibre communication, high data rate optical networking, security imaging (THz) and radio-astronomy.

So far, two main types of high speed detectors have emerged. One is using a technique to match the optical velocity and the electrical velocity in a waveguide structure ${ }^{1}$. This travelling wave structure offered a $3 \mathrm{~dB}$ bandwidth of $50 \mathrm{GHz}$ with a responsivity of $0.2 \mathrm{~A} / \mathrm{W}^{2}$. The second is using an electron-only transfer structure as the electron transfer is faster than that for holes. In Uni-Travelling Carrier structures (UTC) the electrons act as the only active carriers and determine photoresponse. These UTC structures (UTC) allowed a $3 \mathrm{~dB}$ bandwidth of $310 \mathrm{GHz}$ with $0.07 \mathrm{~A} / \mathrm{W}$ responsivity ${ }^{3}$. The UTC structure has also been used in an evanescently coupled waveguide photodetector scheme ${ }^{4}$ to increase the responsivity to $0.7 \mathrm{~A} / \mathrm{W}$ with a $40 \mathrm{GHz} 3 \mathrm{~dB}$ bandwidth ${ }^{5}$. However neither of these detectors offers high responsivity and very high bandwidth at the same time.

In this paper we report a waveguide UTC device with a $-3 \mathrm{~dB}$ electrical bandwidth of greater than $108 \mathrm{GHz}$ (measurement limited), a record responsivity for this bandwidth of $0.2 \mathrm{~A} / \mathrm{W}$ and up to $-5 \mathrm{dBm}$ extracted electrical power. We also show results with an integrated resonant antenna with extracted power of $148 \mu \mathrm{W}$ at $457 \mathrm{GHz}$ and $24 \mu \mathrm{W}$ at 914 GHz.

\section{THE STRUCTURE}

Figure 1, shows a schematic of the UTC epitaxial structure. The UTC structure used for this work was designed to offer both relatively high coupling from an optical fibre into the detector and short absorption length to reduce the parasitic capacitance. This resulted in an absorption layer thickness such that the carrier transit limited $3 \mathrm{~dB}$ bandwidth was about $340 \mathrm{GHz}$. The length of the waveguide device necessary to absorb $90 \%$ of the incoming light was calculated to be 15 
$\mu \mathrm{m}$. Considering the characteristics of the structure this will correspond to a $18 \mathrm{fF}$ parasitic capacitance, thus giving a parasitic capacitance limited bandwidth of $350 \mathrm{GHz}$ with a $50 \Omega$ load the bandwidth is most likely to be limited by the electrical characteristics of the fabricated device as the RC limit of the bandwidth for such a capacitance would be 354 $\mathrm{GHz}$, thus of the same order of magnitude as the carrier transit limited $3 \mathrm{~dB}$ bandwidth. However, once fabricated the waveguide device was measured to have a parasitic capacitance of only $20-25 \mathrm{fF}$, which gives a capacitance limited $3 \mathrm{~dB}$ bandwidth of $254 \mathrm{GHz}$ with a $50 \Omega$ load, which should be our main limitation on the bandwidth of the detector.

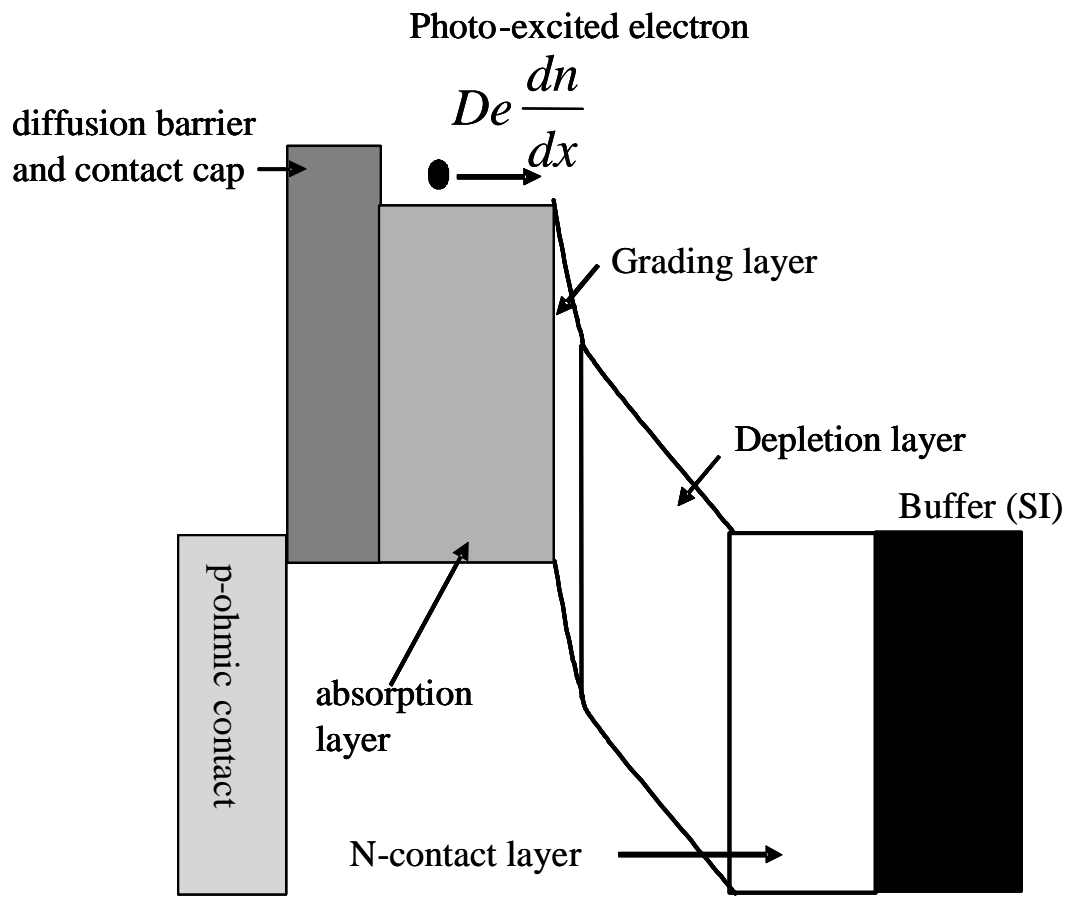

Figure 1: Schematic epitaxial structure

\section{THE PHOTODETECTOR RESPONSIVITY AND BANDWIDTH}

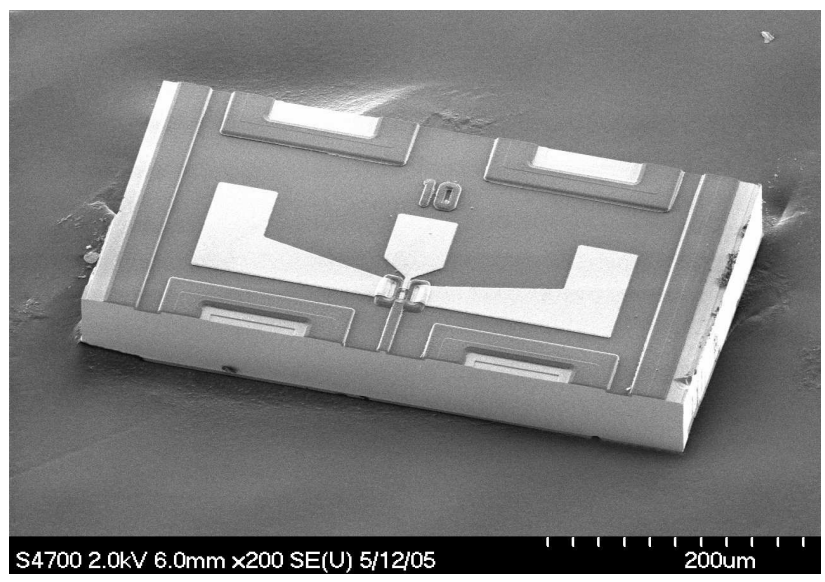

Figure 2: Picture of the fast photodetector with contact pattern for the use of a coplanar probe 
Figure 2 shows a picture of the photodetector with contacts for a coplanar probes and the waveguide to couple the light into the detector. The waveguide allowed for a $40 \%$ coupling of the light $(1550 \mathrm{~nm})$ coming out of a lensed fibre. The contacts where designed to be used with a ground-signal-ground coplanar probe with a $150 \mu \mathrm{m}$ spacing between the pads. Two probes were used to test the device one for measurement up to $65 \mathrm{GHz}$ and one for measurement between 70 $\mathrm{GHz}$ and $110 \mathrm{GHz}$.

\section{III.1. Experimental measurement systems}

The experimental measurements of the waveguide detector were made using two different systems.

The first was a Lightwave Component Analyser (LCA), used for studies up to $40 \mathrm{GHz}$. The output of the LCA is a 10 $\mathrm{dBm}$ power level optical signal at $1550 \mathrm{~nm}$. At the end of the lensed fibre this drops to $9 \mathrm{dBm}$. Then by taking the result of simulation for the coupling into the waveguide we can estimate the coupled power into the photodetector to be $5 \mathrm{dBm}$. After calibration the LCA measured the detector frequency dependent photo-response. The calibration was made with the probe. However this was not a full calibration as it was only made in short and open circuit and not into a load. Note that the $5 \mathrm{dBm}$ estimated input power generated a $635 \mu \mathrm{A}$ current.

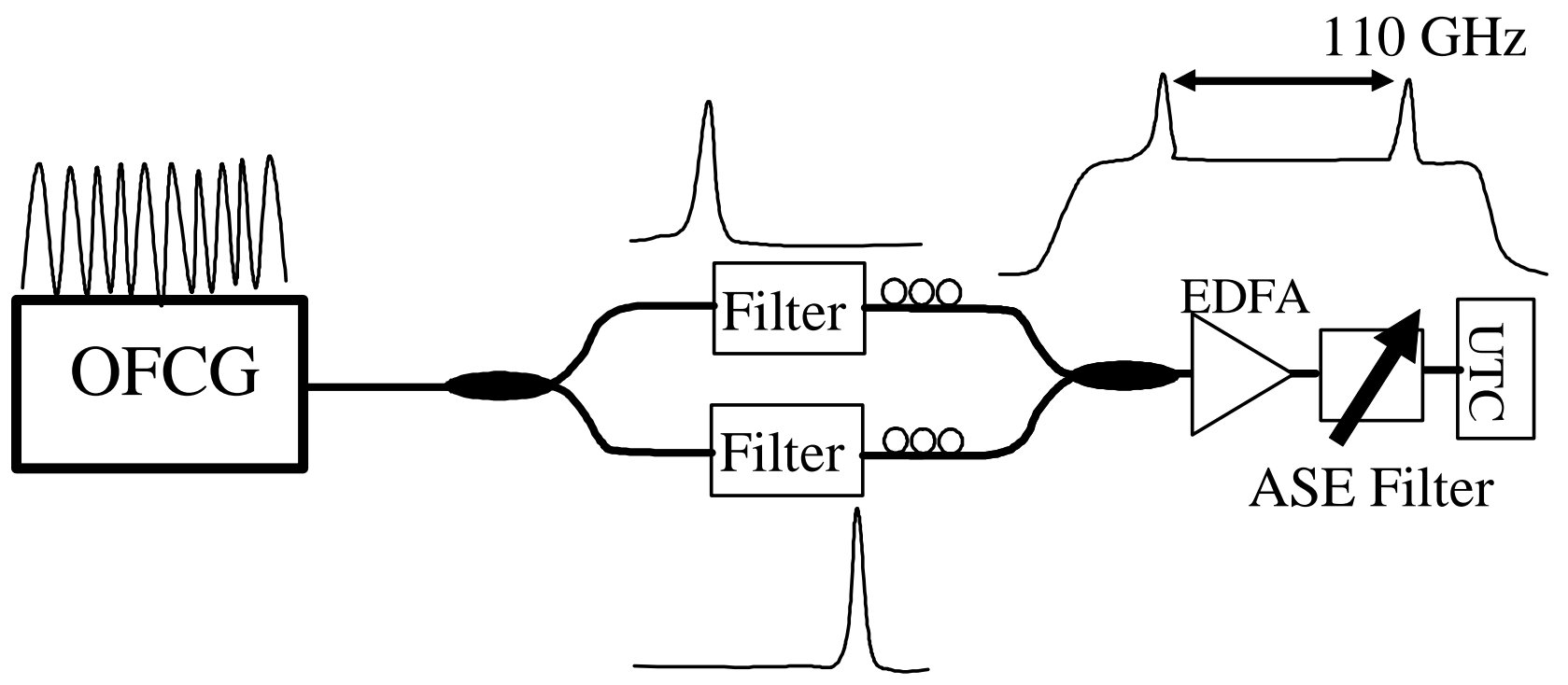

Figure 3: Experimental system used for measurements above $40 \mathrm{GHz}$

The second, shown in figure 3, used a signal from an heterodyne system based on an optical frequency comb generator ${ }^{6}$, from which two lines were filtered out by tuneable narrow-band filters. The two lines were then combined and amplified to generate a signal at a frequency determined by their separation. The use of such a system allows for the generation of high purity millimetre-wave frequencies ${ }^{7}$. The total saturated output power from the EDFA was $21 \mathrm{dBm}$, thus the estimated power coupled into the device was $17 \mathrm{dBm}$. The measured photocurrent at this level of power was $10 \mathrm{~mA}$. However the filter used in this experiment where relatively broad (several comb lines were transmitted) thus the generated signal comprised several beating frequencies. Therefore not all the generated power was at the frequency of interest of the measurement. The resulting signal measured by the probe was then sent to a spectrum analyser.

As stated above, the device was probed with coplanar probes (one for signals from 0 to $65 \mathrm{GHz}$ using coaxial electrical connection and one for signals from 70 to $110 \mathrm{GHz}$ using waveguide electrical connection). The probes were connected to different calibrated harmonic microwave mixers to down-convert the high frequency signals for display on a spectrum analyzer. This resulted in losses of up to $45 \mathrm{~dB}$ at $110 \mathrm{GHz}(3 \mathrm{~dB}$ from the probe and $42 \mathrm{~dB}$ from the mixer). The following results are including a frequency dependent loss correction. 


\section{III.2. Experimental results}

Using the LCA we measured the dependence of bandwidth with reverse bias and the response up to $40 \mathrm{GHz}$. The measurements, shown in figure 4 , demonstrated that as expected with no reverse bias the $-3 \mathrm{~dB}$ bandwidth was $1 \mathrm{GHz}$, at $-1 \mathrm{~V}$ it was $20 \mathrm{GHz}$ and at $-2 \mathrm{~V}$ the response was essentially flat $(<1 \mathrm{~dB}$ decrease) up to $40 \mathrm{GHz}$. There was no improvement in bandwidth when the bias was made more negative than $-2 \mathrm{~V}$. This was therefore used as the optimum bias for the rest of the experiments. This showed as well that about $10 \mu \mathrm{W}$ power could be extracted from the photodiode with the $5 \mathrm{dBm}$ optical excitation $(10 \mathrm{dBm}$ out of the source, $1 \mathrm{dBm}$ lost in connection and transmission, $4 \mathrm{dBm}$ lost in coupling).

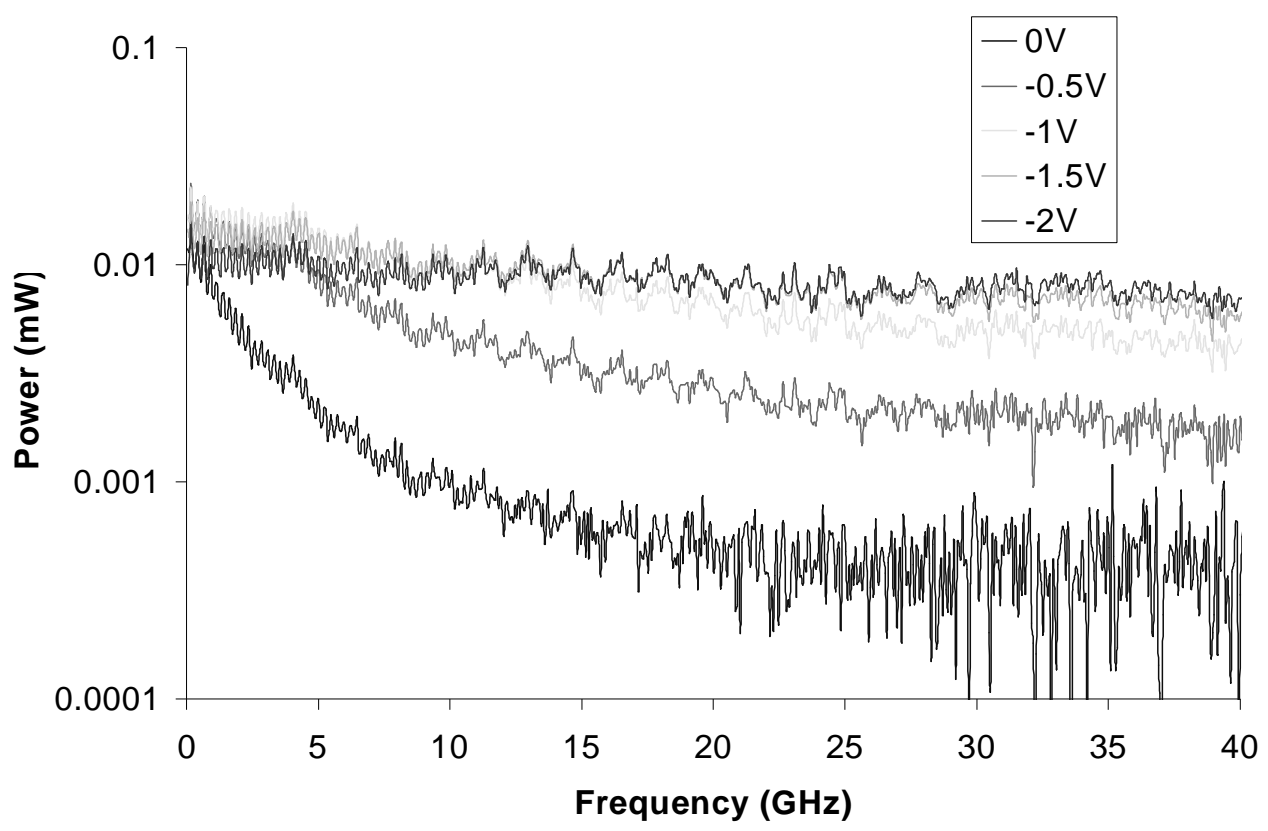

Figure 4: Photodetector response up to $40 \mathrm{GHz}$ with reverse bias from 0 to $2 \mathrm{~V}$

To measure the response at higher frequency the heterodyne system was use. As we were interested in the relative response of the photodetector up to $110 \mathrm{GHz}$ with $-2 \mathrm{~V}$ bias, points were taken below $40 \mathrm{GHz}$ with the heterodyne measurement system in order to relate them with the previous measurements with the LCA. As seen in figure 5, the experiment showed that the response remains above $-3 \mathrm{~dB}$ up to $108.2 \mathrm{GHz}$ within the error of the measurement. Given the limitation of the coplanar probes and the microwave mixers no measurement was made above $110 \mathrm{GHz}$. This gives us confidence in claiming that we are limited by our measurement system and the actual $3 \mathrm{~dB}$ bandwidth of this detector should be higher than $110 \mathrm{GHz}$.

Figure 6 shows the mean photocurrent at $110 \mathrm{GHz}$ as a function as the estimated coupled input optical power. This corresponds to a measured responsivity of $0.2 \mathrm{~A} / \mathrm{W}$. The measured millimetre-wave power was up to $-5 \mathrm{dBm}$ at 108.2 GHz. From the $10 \mathrm{~mA}$ mean photocurrent measured and the measured frequency response one would expect up to 2 $\mathrm{dBm}$ extracted power. However as stated above the filters in the heterodyne system were not ideal and the power was distributed over different beating frequency, thus the lower than expected extracted power.

In addition, the response was not saturated with the $50 \mathrm{~mW}$ optical input $(125 \mathrm{~mW}$ in the fibre $40 \%$ coupling to the detector). Previous measurement (DC) on the same structure grown on N-doped substrate (higher parasitic capacitance devices) showed a higher $0.28 \mathrm{~A} / \mathrm{W}$ responsivity with no saturation at up to $100 \mathrm{~mW}$ (estimated with a $40 \%$ coupling) optical input (28 mA photocurrent). Therefore we expect that this device has the potential to generate extracted electrical power of the order of $10 \mathrm{dBm}$ at $110 \mathrm{GHz}$, for a fully modulated input signal. 


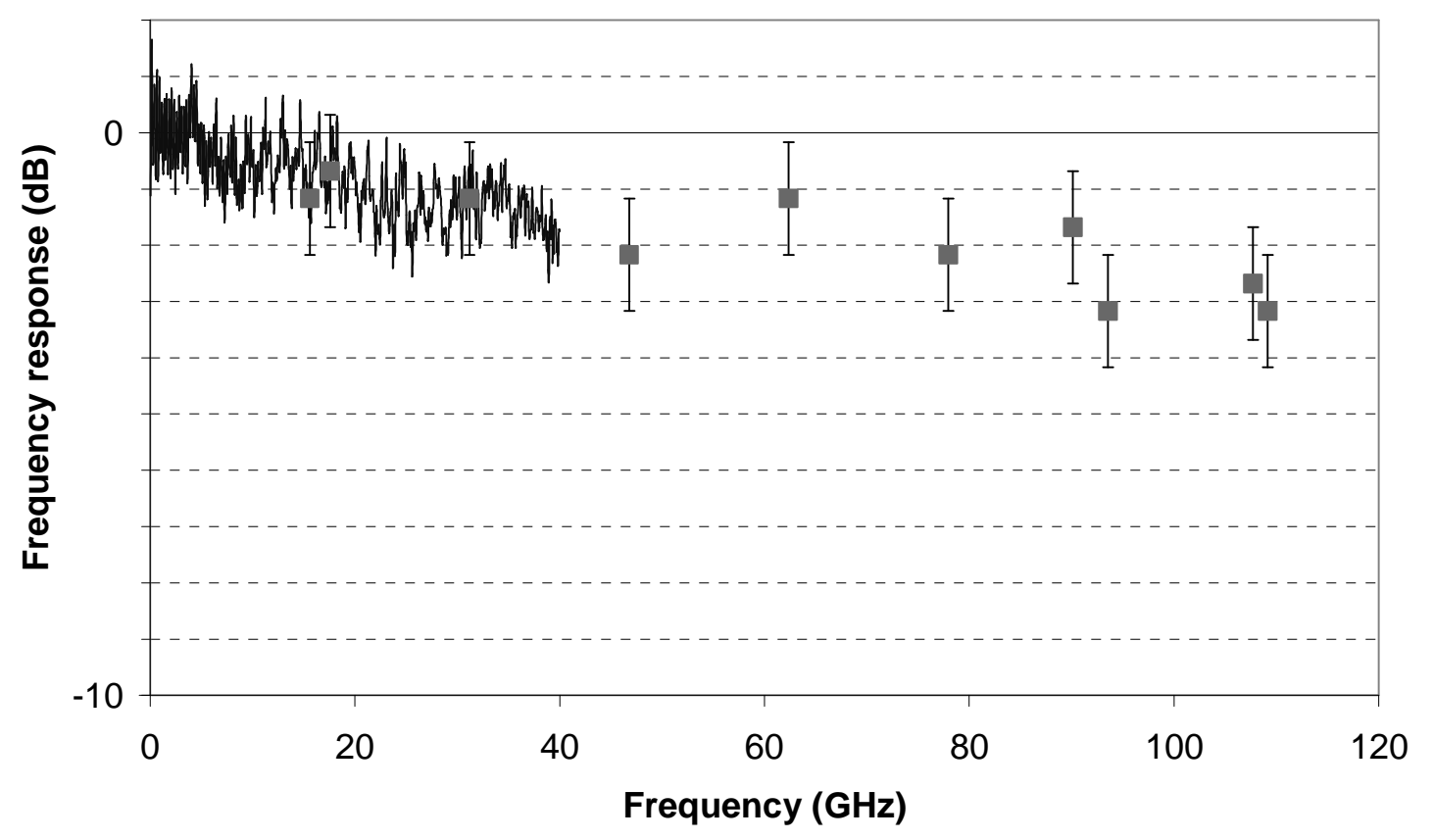

Figure 5: Relative UTC-PD response up to $110 \mathrm{GHz}$

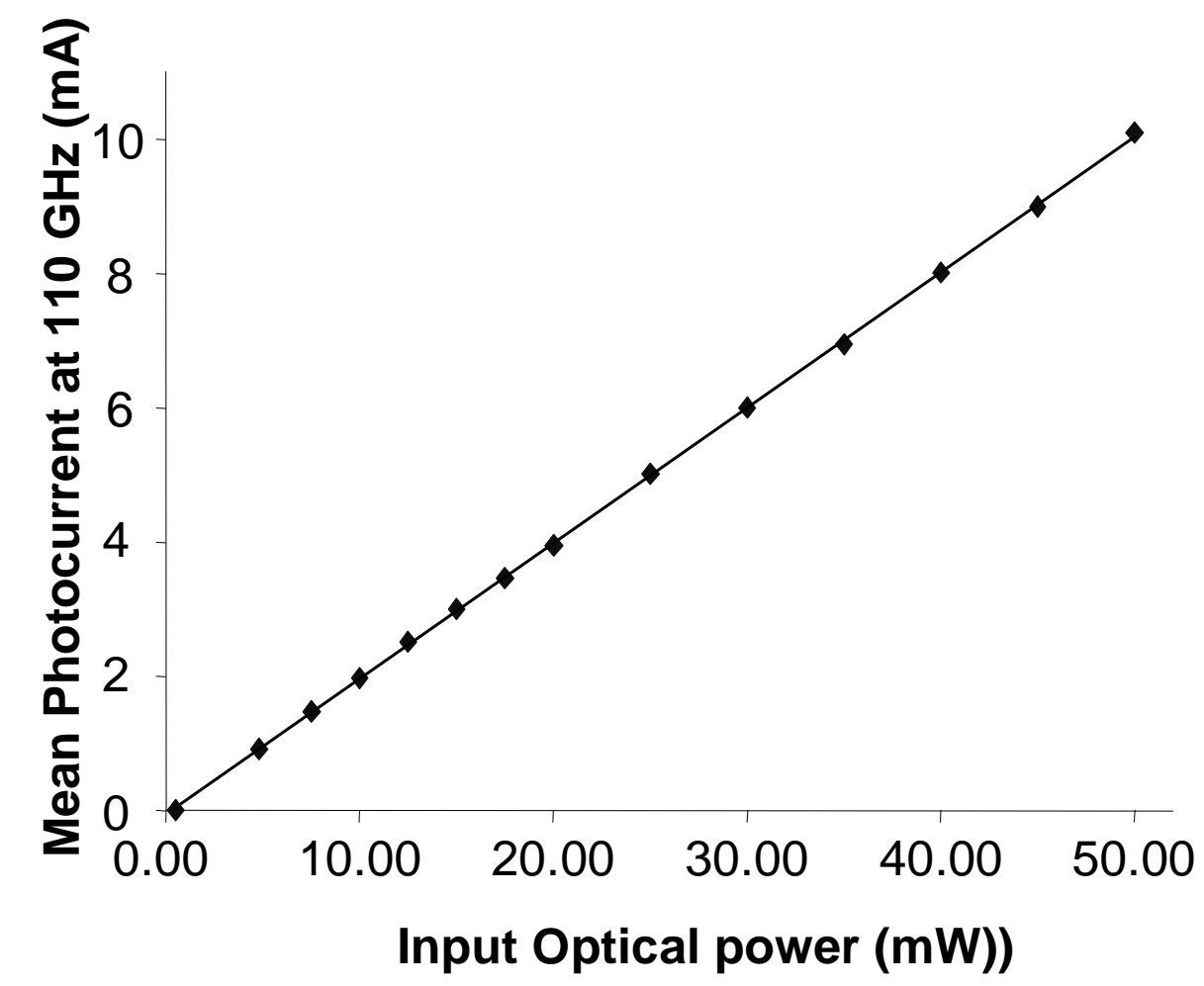

Figure 6: Mean photocurrent response at $110 \mathrm{GHz}$ 


\section{MILLIMETRE WAVE HETERODYNE GENERATION}

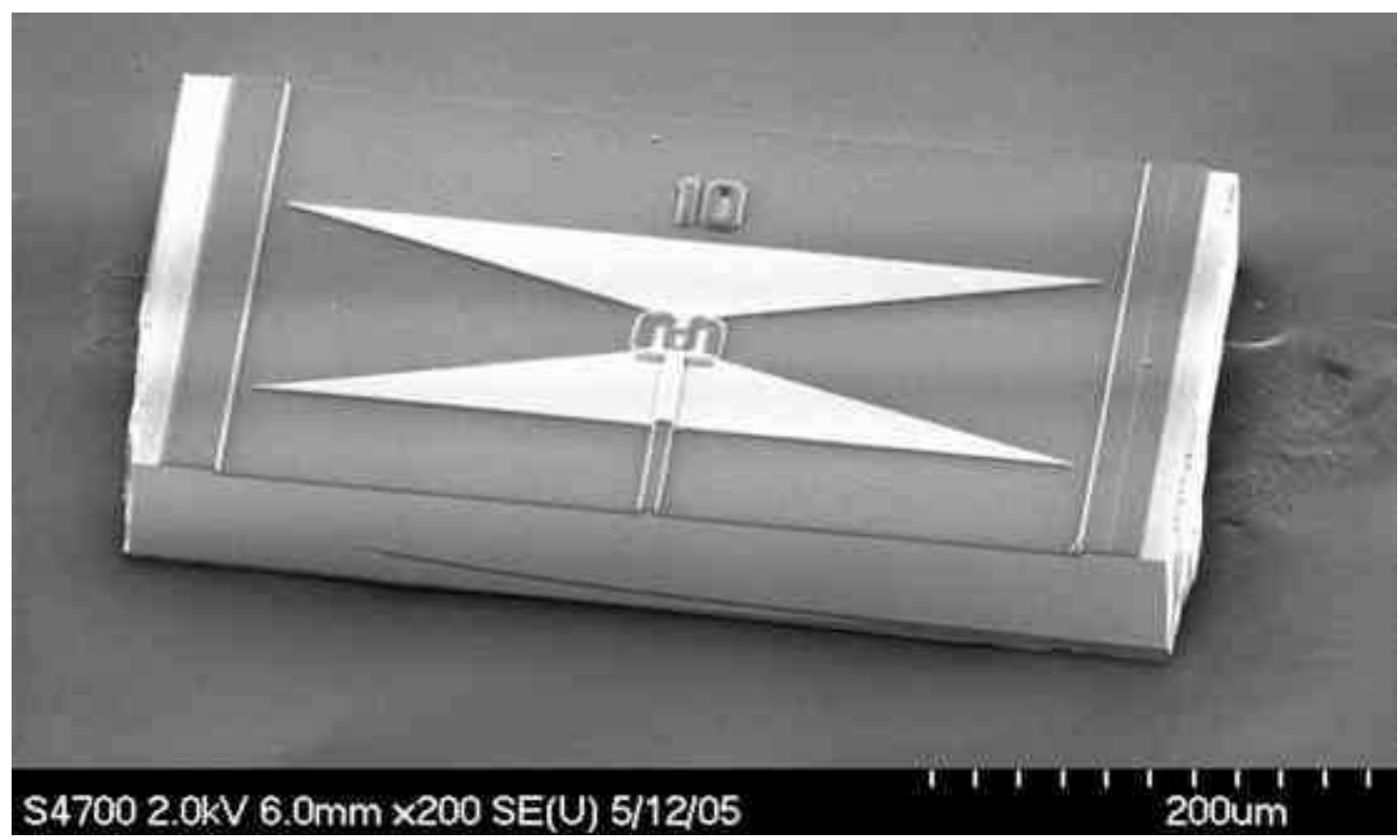

Figure 7: Picture of the photodetector integrated with a bowtie antenna

As shown in figure 7, the photodetector was integrated with an antenna. The one shown in figure 7 is a broadband bowtie antenna with a peak at $800 \mathrm{GHz}$. The detector was also integrated with a resonant sub-millimetre-wave antenna structure. This allowed measuring the device using free-space techniques.

Figure 8 shows the measurement system using the heterodyne system (with high selectivity filters) to generate high purity frequencies from $100 \mathrm{GHz}$ to $1 \mathrm{THz}$. The optical power send to the photodiode generated a $10 \mathrm{~mA}$ photocurrent. The signal emitted from the antenna was measured using a $\mathrm{THz}$ power meter based on a photo-acoustic detector for powers above $10 \mu \mathrm{W}$ and a bolometer for power under $10 \mu \mathrm{W}$. Extra care was taken to filter any residual and parasitic energy that could be measured by the detector. The continuous signal from the EDFA ASE was also estimated and subtracted.

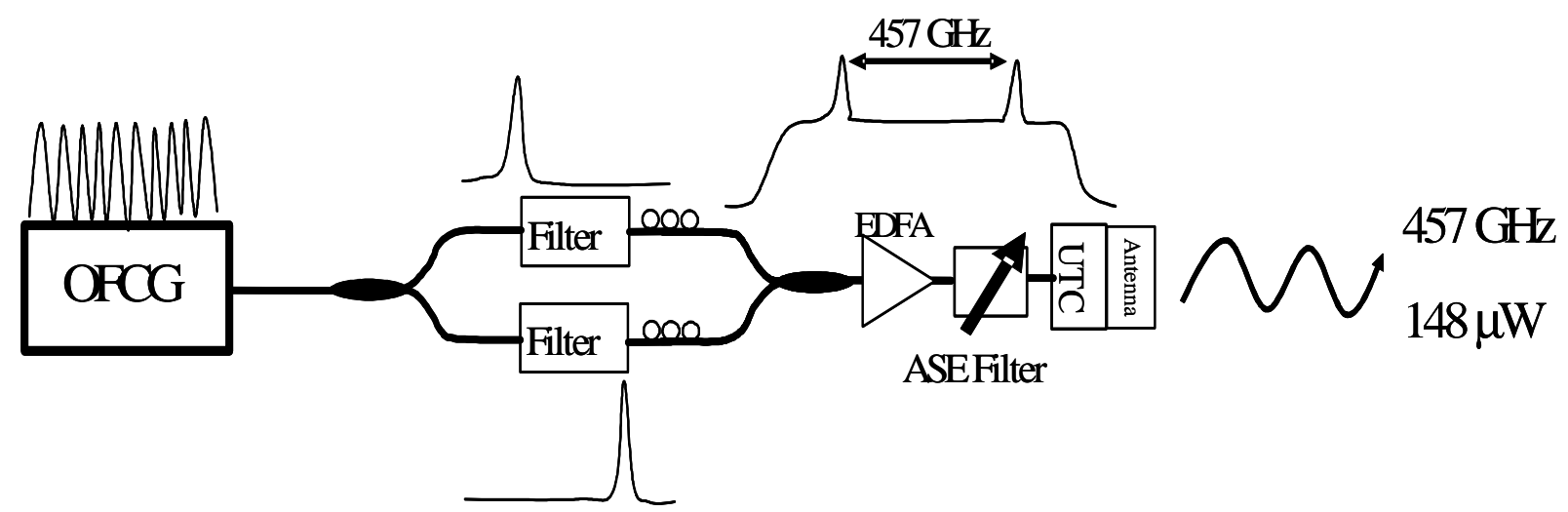

Figure 8: Experimental system for heterodyne generation of $\mathrm{THz}$ signal from the photodetector integrated with antenna. 


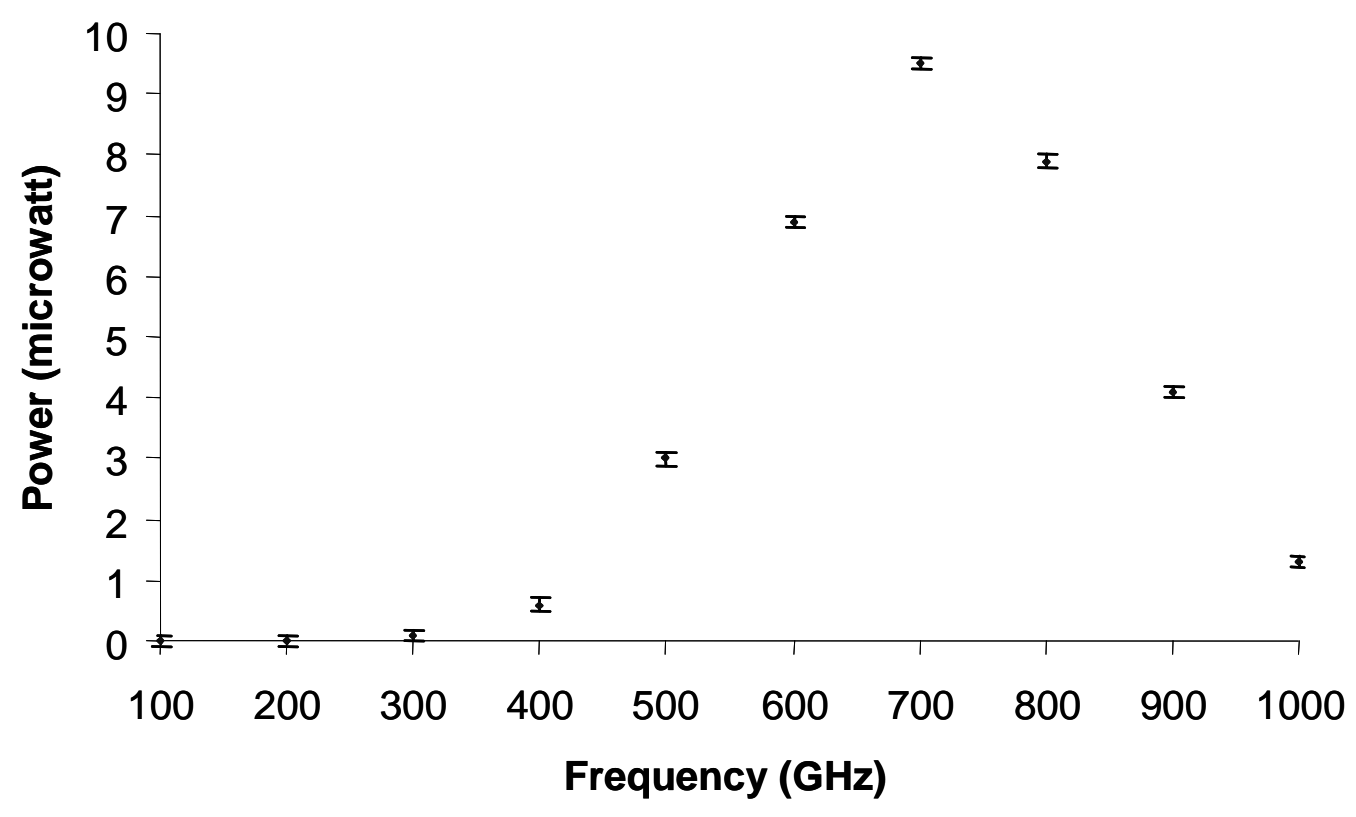

Figure 9: Signal emitted from the bowtie antenna as a function of the Frequency

Figure 9 shows the measured extracted millimetre wave power at different heterodyne frequency. One can see the response of the broadband antenna resulted in a broadband emission around $700 \mathrm{GHz}$. The maximum extracted power was at $700 \mathrm{GHZ}$ with $9.5 \mu \mathrm{W}$ and there was still more than $1 \mu \mathrm{W}$ at $1 \mathrm{THz}$. When the device was integrated with a resonant antenna more power could be extracted but only in a narrow band around the resonant frequency. The antenna was designed to have two resonant frequencies around $450 \mathrm{GHz}$ and $900 \mathrm{GHz}$. During testing, two resonant peaks of emission at $457 \mathrm{GHz}$ and $914 \mathrm{GHz}$ were obtained with record breaking power outputs of $148 \mu \mathrm{W}$ and $24 \mu \mathrm{W}$ respectively.

\section{CONCLUSION}

This work demonstrates a record high responsivity $(0.2 \mathrm{~A} / \mathrm{W})$ UTC based waveguide photodiode with up to $-5 \mathrm{dBm}$ extracted output power at $110 \mathrm{GHz}$. It also achieved up to $148 \mu \mathrm{W}$ emitted at $457 \mathrm{GHz}$ when integrated with a resonant antenna, and up to $9 \mu \mathrm{W}$ when integrated with a broadband bowtie antenna. However measurement with DC excitation showed that the saturation power of the photodetector is above $200 \mathrm{~mW}$ (optical power) coupled into the device. Furthermore the parasitic capacitance measurements suggest that the $3 \mathrm{~dB}$ bandwidth of the device should be at least 250 $\mathrm{GHz}$ for a $50 \Omega$ load. Therefore, we expect that this structure can provide much higher bandwidth and higher power. We believe that we should be able to extract up to $7 \mathrm{dBm}$ at $110 \mathrm{GHz}$ (with $200 \mathrm{~mW}$ coupled optical power) and emit almost $300 \mu \mathrm{W}$ at $457 \mathrm{GHz}$ from the photodetector integrated with an antenna.

Future work will concentrate on improving the balance between coupling and bandwidth. 


\section{REFERENCES}

${ }^{1}$ K.S Giboney, M. J. W. Rodwell, J. E. Bowers, “Travelling-wave photodetector theory,” IEEE Trans. Microwave Theory and Tech., 45, pp 1310-19, 1997

${ }^{2}$ A. Stöhr, R. Heinzelmann, K. Hagedorn, R. Gusten, F. Schafer, H. Stuer, F. Siebe, P. van der Wal, V. Krozer, M. Feiginov, D. Jager, “Integrated $460 \mathrm{GHz}$ photonic transmitter module," Electron. Letters, 37, pp. 1347-48, 2001

${ }^{3}$ H. Ito, S. Kodama, Y. Muramoto, T. Furuta, T. Nagatsuma, T. Ishibashi, "High-speed and high-output InP-InGaAs unitraveling-carrier photodiodes," IEEE J. of Selected Topics in Quantum Electron, 10, pp 709-727, 2004

${ }^{4}$ J. C. Campbell, S. Demiguel. N. Li, "High-Speed Photodetectors," ECOC 2005 (invited paper), Glasgow, 2005

${ }^{5}$ M. Achouche, F. Blache, J-G. Provost, E. Derouin, D. Carpentier, S. Vuye, L. Giraudet, M. Goix, F. Jorge, "High speed and high responsivity UTC photodiode module for $>40 \mathrm{~GB} / \mathrm{s}$ optical receivers," OFC 2004, paper TuM4, Los Angeles, 2004

${ }^{6}$ S. Bennett, B. Cai, E. Burr, O. Gough and A. J. Seeds, "1.8 Terahertz bandwidth, zero frequency error, tunable optical comb generator for DWDM applications,” IEEE Photon. Technol. Lett., 11, pp. 551-553, 1999

${ }^{7}$ S. Fukushima, C.F.C. Silva, Y. Muramoto, A.J. Seeds, "Optoelectronic synthesis of milliwatt-level multi-octave millimeter-wave signals using an optical frequency comb generator and a unitraveling-carrier photodiode," IEEE Photonics Technology Letters, 13, pp. 720-722, 2001 